Pacific Journal of Mathematics

DISTRIBUTION ESTIMATES OF BARRIER-CROSSING
PROBABILITIES OF THE YEH-WIENER PROCESS 


\title{
DISTRIBUTION ESTIMATES OF BARRIER-CROSSING PROBABILITIES OF THE YEH-WIENER PROCESS
}

\author{
C. Park AND D. L. Skoug
}

Let $Q=[0, S] \times[0, T]$ be a rectangle and $\{X(s, t): s, t \geqq 0\}$ be the two-parameter Yeh-Wiener process. This paper finds probabilities of $X(s, t)$ crossing barriers of the type $a s t+b s+$ $c t+d$ on the boundary $\partial Q$. These probabilities give lower bounds for the yet unknown probabilities of $X(s, t)$ crossing $a s t+b s+c t+d$ on $Q$. The paper also discusses sharper bounds for the latter probabilities.

1. Introduction. Let $\{X(s, t): s, t \geqq 0\}$ be the standard YehWiener process of two parameters such that it is a separable real Gaussian stochastic process satisfying:

$$
X(s, t)=0 \text { a.s. if } s \text { or } t \text { is } 0,
$$

the expected value $E\{X(s, t)\}=0$ at every $s, t \geqq 0$,

$$
E\left\{X(s, t) X\left(s^{\prime}, t^{\prime}\right)\right\}=\min \left(s, s^{\prime}\right) \cdot \min \left(t, t^{\prime}\right) .
$$

Further properties of the process are found in Yeh's [8] and [9].

For the square $D=[0,1] \times[0,1]$ and its boundary $\partial D$, Paranjape and Park [6] showed that the probability

$$
P\left\{\sup _{\partial D} X(s, t) \geqq \lambda\right\}=3 N(-\lambda)-e^{4 \lambda^{2}} N(-3 \lambda), \quad \lambda \geqq 0,
$$

where $N(\cdot)$ stands for the standard normal distribution function. This probability is a lower bound of the yet unknown probability, $P\left\{\sup _{D} X(s, t) \geqq \lambda\right\}$. It is known (see [4] or [7]) that

$$
P\left\{\sup _{D} X(s, t) \geqq \lambda\right\} \leqq 4 P\{X(1,1) \geqq \lambda\}=4 N(-\lambda) .
$$

Recently Chan [1] showed that, for every $\varepsilon>0$,

$$
P\left\{\sup _{D} X(s, t) \geqq \lambda\right\} \leqq N(\varepsilon)^{-1} P\left\{\sup _{D} X(s, t) \geqq \lambda-\varepsilon\right\} .
$$

By the same technique as he used in his paper, the upper bound can easily be improved to $N(\varepsilon)^{-1} P\{\sup X(1, t) \geqq \lambda-\varepsilon: 0 \leqq t \leqq 1\}=$ $2 N(-\lambda+\varepsilon) / N(\varepsilon)$. However it turns out to be that even this improved upper bound is not as good as $4 N(-\lambda)$ for any $\varepsilon>0$. In fact

$$
4 N(-\lambda)<N(\varepsilon)^{-1} P\left\{\sup _{0 \leqq t \geqq 1} X(1, t) \geqq \lambda-\varepsilon\right\}, \quad \varepsilon>0,
$$


and

$$
\lim _{\varepsilon \rightarrow 0^{+}} N(\varepsilon)^{-1} P\left\{\sup _{0 \leqq t \leqq 1} X(1, t) \geqq \lambda-\varepsilon\right\}=4 N(-\lambda) .
$$

More recently Goodman [3] showed that for $\lambda \geqq 0$,

$$
2\left\{N(-\lambda)+\lambda \int_{\lambda}^{\infty} N(-s) d s\right\} \leqq P\left\{\sup _{D} X(s, t) \geqq \lambda\right\} .
$$

Obviously the left-hand side of (1.7) is a much better lower bound of $P\left\{\sup _{D} X(s, t) \geqq \lambda\right\}$ than (1.4). He subsequently proves that

$$
\lim _{\lambda \rightarrow \infty} \frac{2\left\{N(-\lambda)+\lambda \int_{\lambda}^{\infty} N(-s) d s\right.}{4 N(-\lambda)}=1,
$$

thus showing that both $2\left\{N(-\lambda)+\lambda \int_{\lambda}^{\infty} N(-s) d s\right\}$ and $4 N(-\lambda)$ are very good approximations of $P\left\{\sup _{D} X(s, t) \geqq \lambda\right\}$ for all sufficiently large $\lambda$.

The main purpose of this paper is to generalize the above results for more general barriers, namely, to find a formula for

$$
P\left\{\sup _{\partial D} X(s, t)-(a s t+b s+c t+d) \geqq 0\right\}, \quad a, b, c, d \geqq 0,
$$

and then find a lower bound for $P\left\{\sup _{D} X(s, t)-(a s t+b s+c t+d) \geqq 0\right\}$ for which (1.7) is a special case. It is apparent that for all $a, b, c, d \geqq 0$

$$
P\left\{\sup _{D} X(s, t)-(a s t+b s+c t+d) \geqq 0\right\} \leqq 4 N(-d) .
$$

In addition we obtain a formula for

$$
P\left\{\sup _{\partial D}|X(s, t)|-(a s t+b s+c t+d) \geqq 0\right\}, \quad a, b, c, d \geqq 0 .
$$

Some results on two-parameter Brownian bridge are also included.

2. Some lemmas. To avoid unnecessary repetitions in the proofs of the theorems, the following lemmas are given. Throughout this paper $W(t)$ and $X(s, t)$ will denote the standard Wiener process and the Yeh-Wiener process, respectively.

Lemma 1. (Doob [2: p. 398]). If $a \geqq 0, b>0, \alpha \geqq 0, \beta>0$, then

$$
\begin{array}{r}
P\left\{\sup _{0 \leqq t<\infty}[W(t)-(a t+b)] \geqq 0 \text { or } \inf _{0 \leqq t<\infty}[W(t)+\alpha t+\beta] \leqq 0\right\} \\
=\sum_{m=1}^{\infty} \exp \left\{-2\left[m^{2} a b+(m-1)^{2} \alpha \beta+m(m-1)(a \beta+\alpha b)\right]\right\} \\
+\exp \left\{-2\left[(m-1)^{2} a b+m^{2} \alpha \beta+m(m-1)(a \beta+\alpha b)\right]\right\}
\end{array}
$$




$$
\begin{aligned}
& -\exp \left\{-2\left[m^{2}(a b+\alpha \beta)+m(m-1) \alpha \beta+m(m+1) \alpha b\right]\right\} \\
& -\exp \left\{-2\left[m^{2}(a b+\alpha \beta)+m(m-1) a \beta+m(m-1) \alpha b\right]\right\}
\end{aligned}
$$

LEMma 2. Let $f(t)$ be a Borel measurable function. Then for each Borel set $E$ of real numbers,

$$
\begin{aligned}
& P\{W(t)-f(t) \in E, 0<t \leqq 1 \mid W(1)=u\} \\
& \quad=P\left\{W(t)+u-(t+1) f\left(\frac{1}{t+1}\right) \in \frac{1}{t} E, 0<t<\infty\right\} .
\end{aligned}
$$

Proof. The basic technique used here is the same as the one used by Malmquist in [5]. Observe that $W(t)$ and $t W(1 / t)$ are equivalent processes for $t>0$. Thus, the left-hand side of (2.1) reduces to

$$
\begin{gathered}
P\left\{W\left(\frac{1}{t}\right)-\frac{1}{t} f(t) \in \frac{1}{t} E, 0<t \leqq 1 \mid W(1)=u\right\} \\
=P\left\{W\left(\frac{1}{t}\right)-W(1)-\left[\frac{1}{t} f(t)-u\right]\right. \\
\left.\in \frac{1}{t} E, 0<t \leqq 1 \mid W(1)=u\right\} .
\end{gathered}
$$

Upon using the fact that $W(1 / t-1)$ and $W(1 / t)-W(1)$ are equivalent processes for $t>0$, and $W(1 / t)-W(1)$ and $W(1)$ are independent for $1 \geqq t>0$, we have the result by the transformation $1 / t-1 \rightarrow t$.

LEMMA 2.a. If $f(t)$ is a Borel measurable function on [0,1], then

$$
\begin{aligned}
& P\left\{\sup _{0 \leqq t \leqq 1}|X(1, t)|-f(t) \geqq 0 \mid X(1,1)=u\right\} \\
& \quad=P\left\{\sup _{0 \leqq t<\infty}|X(1, t)+u|-(t+1) f\left(\frac{1}{t+1}\right) \geqq 0\right\},
\end{aligned}
$$

and the same holds for $X(t, 1)$.

LemMa 3. Let $f(s, t)$ be a Borel measurable function on $D$. Then for each Borel set $E$ of real numbers,

$$
\begin{aligned}
P\{X(s, t) & \left.-f(s, t) \in E,(s, t) \in(0,1]^{2} \mid X(1,1)=u\right\} \\
= & P\{X(s+1, t+1)-X(1,1) \\
- & {\left.\left[(s+1)(t+1) f\left(\frac{1}{s+1}, \frac{1}{t+1}\right)-u\right] \in \frac{E}{s t},(s, t) \in(0, \infty)^{2}\right\} . }
\end{aligned}
$$


Proof. This lemma is a two-parameter analogue of Lemma 2, and it can be proved similarly by observing that $X(s, t)$ and $s t X(1 / s, 1 / t)$ are equivalent processes for $s, t>0$.

LEMMA 4. Let $f(t)$ and $g(t)$ be any Borel measurable functions on $[0,1]$. Then for any Borel sets $E_{1}$ and $E_{2}$ of real numbers,

$$
\begin{gathered}
P\left\{X(s, 1)-f(s) \in E_{1}, X(1, t)-g(t) \in E_{2},(s, t) \in D \mid X(1,1)=u\right\} \\
=P\left\{X(s, 1)-f(s) \in E_{1}, 0 \leqq s \leqq 1 \mid X(1,1)=u\right\} \\
\cdot P\left\{X(1, t)-g(t) \in E_{2}, 0 \leqq t \leqq 1 \mid X(1,1)=u\right\} .
\end{gathered}
$$

Proof. Observe first that $X(s, 1)$ and $s X(1 / s, 1)$ are equivalent standard Wiener processes for $s>0$, and so are $X(1, t)$ and $t X(1,1 / t)$ for $t>0$. Now $s[X(1 / s, 1)-X(1,1)+u]$ and $t[X(1,1 / t)-X(1,1)+u]$ are independent processes for $1 \geqq s, t>0$, and they are also independent of $\{X(s, t):(s, t) \in D\}$. Hence (2.2) gives:

$$
\begin{gathered}
P\left\{X(s, 1)-f(s) \in E_{1}, X(1, t)-g(t) \in E_{2},(s, t) \in D \mid X(1,1)=u\right\} \\
=P\left\{s[X(1 / s, 1)-X(1,1)+u]-f(s) \in E_{1}, 0<s \leqq 1\right\} \\
\cdot P\left\{t[X(1,1 / t)-X(1,1)+u]-g(t) \in E_{2}, 0<t \leqq 1\right\}
\end{gathered}
$$

But the two probabilities on the right-hand side of (2.3) are equal to $P\left\{X(s, 1)-f(s) \in E_{1}, 0 \leqq s \leqq 1 \mid X(1,1)=u\right\}$ and $P\left\{X(1, t)-g(t) \in E_{2}\right.$, $0 \leqq t \leqq 1 \mid X(1,1)=u\}$ respectively, and hence the proof is complete.

3. Main results and proofs. In what follows $\{X(s, t): s, t \geqq 0\}$ will be used exclusively for the Yeh-Wiener process.

THEOREM 1. If $a, b, c, d \geqq 0$, then with $\bar{a}=a+b+c+d$,

$$
\begin{aligned}
P\left\{\sup _{\partial D}\right. & X(s, t)-(a s t+b s+c t+d) \geqq 0\} \\
= & N(-\bar{a})+e^{-2(a+b)(c+d)} N(a+b-c-d) \\
& +e^{-2(a+c)(b+d)} N(a-b+c-d) \\
& -e^{2(d-a)(b+c+2 d)} N(a-b-c-3 d) .
\end{aligned}
$$

Proof. First observe that

$$
\begin{aligned}
P_{1} \equiv & P\left\{\sup _{\partial D} X(s, t)-(a s t+b s+c t+d) \geqq 0\right\} \\
= & P\left\{\sup _{0 \leqq s \leqq 1} X(s, 1)-[(a+b) s+(c+d)] \geqq 0\right\} \\
& +P\left\{\sup _{0 \leqq t \leqq 1} X(1, t)-[(a+c) t+(b+d)] \geqq 0\right\}
\end{aligned}
$$




$$
\begin{aligned}
& -P\left\{\sup _{0 \leqq s \leqq 1} X(s, 1)-[(a+b) s+(c+d)] \geqq 0, \sup _{0 \leqq t \leqq 1} X(1, t)\right. \\
& -[(a+c) t+(b+d)] \geqq 0\} .
\end{aligned}
$$

Since $X(s, 1)$ and $X(1, t)$ are equivalent to the standard Wiener process $W(t)$, the first two probabilities on the right of (3.1) can be evaluated explicitly.

Now,

$$
\begin{aligned}
P_{2} \equiv & P\left\{\sup _{0 \leqq s \leqq 1} X(s, 1)-[(a+b) s+(c+d)] \geqq 0, \sup _{0 \leqq t \leqq 1} X(1, t)\right. \\
& -[(a+c) t+(b+d)] \geqq 0\} \\
= & P\{X(1,1) \geqq \bar{a}\} \\
& +\int_{-\infty}^{a+b+c+d} P\left\{\sup _{0 \leqq s \leqq 1} X(s, 1)-[(a+b) s+(c+d)] \geqq 0,\right. \\
& \left.\sup _{0 \leqq t \leqq 1} X(1, t)-[(a+c) t+(b+d)] \geqq 0 \mid X(1,1)=u\right\} d N(u) .
\end{aligned}
$$

Due to the fact that

$$
\begin{aligned}
P\left\{\sup _{0 \leqq s \leqq 1}\right. & X(s, 1)-[(a+b) s+(c+d)] \geqq 0, \sup _{0 \leqq t \leqq 1} X(1, t) \\
- & {[(a+c) t+(b+d)] \geqq 0 \mid X(1,1)=u\} } \\
= & P\left\{\sup _{0 \leqq s \leqq 1} X(s, 1)-[(a+b) s+(c+d)] \geqq 0 \mid X(1,1)=u\right\} \\
& \cdot P\left\{\sup _{0 \leqq t \leqq 1} X(1, t)-[(a+c) t+(b+d)] \geqq 0 \mid X(1,1)=u\right\},
\end{aligned}
$$

we may use Lemma 2 to get

$$
\begin{aligned}
P_{2}= & N(-\bar{a}) \\
+ & \int_{-\infty}^{a+b+c+d} P\left\{\sup _{s \geq 0} X(s, 1)-[(c+d) s+(\bar{a}-u)] \geqq 0\right\} \\
& \cdot P\left\{\sup _{t \geqq 0} X(1, t)-[(b+d) t+(\bar{a}-u)] \geqq 0\right\} d N(u) \\
= & N(-\bar{a}) \\
& +\int_{-\infty}^{a+b+c+d} e^{-2(c+d)(\bar{a}-u)} e^{-2(b+d)(\bar{a}-u)} d N(u) \\
= & N(-\bar{a})+e^{2(d-a)(b+c+2 d)} N(a-b-c-3 d) .
\end{aligned}
$$

The result now readily follows.

CoRollary. If $d \geqq 0$, then 


$$
P\left\{\sup _{\partial D} X(s, t) \geqq d\right\}=3 N(-d)-e^{4 d^{2}} N(-3 d) .
$$

This corollary agrees with the result in [6: p. 877].

THEOREM 2. If $\{Y(s, t):(s, t) \in D\}$ is the two-parameter Brownian bridge, i.e., $\{Y(s, t):(s, t) \in D\}=\{X(s, t):(s, t) \in D \mid X(1,1)=0\}$ and $a, b, c, d \geqq 0$, then

$$
\begin{gathered}
P\left\{\sup _{\partial D} Y(s, t)-(a s t+b s+c t+d) \geqq 0\right\} \\
=e^{-2(b+d) \bar{a}}+e^{-2(b+d) \bar{a}}-e^{-2(b+c+2 d) \bar{a}} .
\end{gathered}
$$

Proof. This follows from (3.2) by setting $u=0$.

THEOREM 3. If $a, b, c \geqq 0$ and $d>0$, then with $\bar{a}=a+b+c+d$ and $\bar{c}=c+d$,

$$
P\left\{\sup _{\partial D} \frac{|X(s, t)|}{a s t+b s+c t+d} \geqq 1\right\}=2 f(a, b, c, d),
$$

where

$$
\begin{aligned}
& f(a, b, c, d)=N(-\bar{a})+\sum_{K=1}^{\infty}(-1)^{k+1}\left[e^{-2(a+b) \bar{c} k} \int_{-\bar{a}-2 \bar{c} k}^{\bar{a}-2 \overline{c k}} d N(u)\right. \\
& \left.\quad+e^{-2(a+c)(b+d) k^{2}} \int_{-\bar{a}-2(b+d) k}^{\bar{a}-2(b+d) k} d N(u)\right] \\
& \quad-\sum_{j, k=1}^{\infty}(-1)^{j+k} e^{-2 \bar{a}\left[\bar{c} j^{2}+(b+d) k^{2}\right]}\left\{e^{2[\bar{c} j+(b+d) k]^{2}}\right. \\
& \left.\quad \times \int_{-\bar{a}-2[\bar{c} j+(b+d) k]}^{\bar{a}-2[\bar{c} j+(b+d) k]} d N(u)+e^{2[\bar{c} j-(b+d) k]^{2}} \int_{-\bar{a}-2[\bar{c} j(b+d) k]}^{\bar{a}-2[\bar{c} j-(b+d) k]} d N(u)\right\} .
\end{aligned}
$$

Proof. Observe that

$$
\begin{aligned}
P_{3}(u) \equiv & P\left\{\sup _{\partial D} \frac{|X(s, t)|}{a s t+b s+c t+d} \geqq 1 \mid X(1,1)=u\right\} \\
= & P\left\{\sup _{0 \leq s \leq 1} \frac{|X(s, 1)|}{(a+b) s+(c+d)} \geqq 1 \quad\right. \text { or } \\
& \left.\sup _{0 \leqq t \leqq 1} \frac{|X(1, t)|}{(a+c) t+(b+d)} \geqq 1 \mid X(1,1)=u\right\} .
\end{aligned}
$$

Upon applying Lemma 4, we obtain

$$
\begin{aligned}
P_{3}(u)= & P\left\{\sup _{0 \leqq s \leq 1} \frac{|X(s, 1)|}{(a+b) s+(c+d)} \geqq 1 \mid X(1,1)=u\right\} \\
& +P\left\{\sup _{0 \leq t \leq 1} \frac{|X(1, t)|}{(a+c) t+(b+d)} \geqq 1 \mid X(1,1)=u\right\}
\end{aligned}
$$




$$
\begin{array}{r}
-P\left\{\sup _{0 \leqq s \leqq 1} \frac{|X(s, 1)|}{(a+b) s+(c+d)} \geqq 1 \mid X(1,1)=u\right\} \\
\cdot P\left\{\sup _{0 \leqq t \leqq 1} \frac{|X(1, t)|}{(a+c) t+(b+d)} \geqq 1 \mid X(1,1)=u\right\} .
\end{array}
$$

Due to Lemma 2.a., it follows

$$
\begin{aligned}
& P\left\{\sup _{0 \leqq s \leqq 1} \frac{|X(s, 1)|}{(a+b) s+(c+d)} \geqq 1 \mid X(1,1)=u\right\} \\
& \quad=P\left\{\sup _{0 \leqq s<\infty} \frac{|X(s, 1)+u|}{(c+d) s+\bar{a}} \geqq 1\right\} \\
& \quad=P\left\{\sup _{0 \leqq s<\infty} X(s, 1)-[(c+d) s+(\bar{a}-u)] \geqq 0\right. \\
& \left.\quad \text { or } \inf _{0 \leqq s<\infty} X(s, 1)+[(c+d) s+(\bar{a}+u)] \leqq 0\right\} .
\end{aligned}
$$

Lemma 1 applied to the last expression gives:

$$
\begin{aligned}
P\left\{\sup _{0 \leqq s<\infty}\right. & X(s, 1)-[(c+d) s(\bar{a}-u)] \geqq 0 \\
& \text { or } \left.\inf _{0 \leqq s<\infty} X(s, 1)+[(c+d) s+(\bar{a}+u)] \leqq 0\right\} \\
= & \sum_{m=1}^{\infty}\left\{e^{-2 \bar{a}(c+d)(2 m-1) 2}\left[e^{2(c+d)(2 m-1) u}+e^{-2(c+d)(2 m-1) u}\right]\right. \\
& \left.-e^{-2 \bar{a}(c+d)(2 m) 2}\left[e^{2(c+d)(2 m) u}+e^{-2(c+d)(2 m) u}\right]\right\} .
\end{aligned}
$$

Therefore

$$
\begin{array}{r}
P\left\{\sup _{0 \leqq s \leqq 1} \frac{|X(s, 1)|}{(a+b) s+(c+d)} \geqq 1 \mid X(1,1)=u\right\} \\
=\sum_{j=1}^{\infty}(-1)^{j+1} e^{-2 \bar{a}(c+d) j^{2}}\left[e^{2(c+d) j u}+e^{-2(c+d) j u}\right]
\end{array}
$$

and

$$
\begin{array}{r}
P\left\{\sup _{0 \leqq t \leqq 1} \frac{|X(1, t)|}{(a+c) t+(b+d)} \geqq 1 \mid X(1,1)=u\right\} \\
=\sum_{k=1}^{\infty}(-1)^{k+1} e^{-2 \vec{a}(b+d) k^{2}}\left[e^{2(b+d) k u}+e^{-2(b+d) k u}\right] .
\end{array}
$$

Since $X(1,1)$ is the standard normal random variable, the result now follows by:

$$
\begin{aligned}
& P\left\{\sup _{\partial D} \frac{|X(s, t)|}{a s t+b s+c t+d} \geqq 1\right\} \\
& \quad=P\{|X(1,1)| \geqq \bar{a}\}+\int_{-\bar{a}}^{\bar{a}} P_{3}(u) d N(u)
\end{aligned}
$$




$$
=2 N(-\bar{a})+\int_{-\bar{a}}^{\bar{a}} P_{3}(u) d N(u)
$$

THEOREM 4. If $a, b, c, d \geqq 0$ and $\bar{a}=a+b+c+d, \bar{b}=b+c+d$, $\bar{c}=c+d$, then for $u<\bar{a}$,

$$
\begin{aligned}
& P_{4} \equiv P\left\{\sup _{D} X(s, t)-(a s t+b s+c t+d) \geqq 0 \mid X(1,1)=u\right\}
\end{aligned}
$$

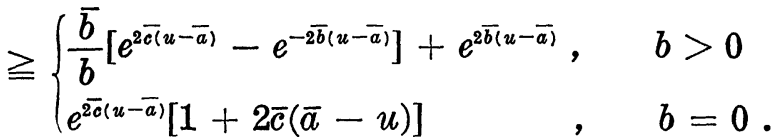

Proof. Upon applying Lemma 3, we obtain

$$
\begin{aligned}
P_{4}= & P\left\{\sup _{s, t \geqq 0} X(s+1, t+1)-X(1, t+1)+X(1, t+1)-X(1,1)\right. \\
& -[d(s+1)(t+1)+c(s+1)+b(t+1)+a-u] \geqq 0\} .
\end{aligned}
$$

Consider the fact that $X(s+1, t+1)-X(1, t+1)$ and $X(1, t+1)-$ $X(1,1)$ are independent processes equivalent to $X(s, t+1)$ and $X(1, t)$, respectively. The latter $X(1, t)$ will be denoted by $X^{*}(1, t)$ to signify that it is independent of $X(s, t+1)$. Due to the fact that $c(s+1) \leqq$ $c(s+1)(t+1)$ for all $c, s, t \geqq 0$, it follows from (3.3)

$$
\begin{aligned}
P_{4} \geqq & P\left\{\sup _{s, t \geqq 0} X(s, t+1)+X^{*}(1, t)-[\bar{c}(t+1) s+\bar{b} t+\bar{a}-u] \geqq 0\right\} \\
\geqq & \int_{u-\bar{a}}^{\infty} P\left\{\sup _{s \geqq 0} X(s, t+1)-[\bar{c}(t+1) s-r] \geqq 0 \mid \sup _{t \geqq 0} X^{*}(1, t)\right. \\
& -(\bar{b} t+\bar{a}-u)=r\} p(r, u) d r,
\end{aligned}
$$

where $p(r, u)$ is the probability density of

$$
\begin{array}{r}
P\left\{\sup _{t \geqq 0} X^{*}(1, t)-(\bar{b} t+\bar{a}-u) \leqq r\right\} \\
= \begin{cases}1-e^{-2 \bar{b}(\bar{a}+r-u)}, & u-\bar{a} \leqq r \\
0 & , \text { otherwise }\end{cases}
\end{array}
$$

Thus

$$
p(r, u)= \begin{cases}2 \bar{b} e^{-2 \bar{b}(\bar{a}+r-u)}, & u-\bar{a} \leqq r \\ 0 & , \quad \text { otherwise }\end{cases}
$$

Observe that the probability in the integrand of (3.4) becomes 


$$
\begin{gathered}
P\left\{\sup _{s \geqq 0} X(s, t+1)-[\bar{c}(t+1) s-r] \geqq 0\right\} \\
= \begin{cases}e^{2 \overline{c r}}, & r \leqq 0 \\
1, & r>0 .\end{cases}
\end{gathered}
$$

Therefore, (3.5) and (3.6) together with (3.4) give

$$
P_{4} \geqq \int_{u-\bar{a}}^{0} e^{\overline{2 c r}} 2 \bar{b} e^{-2 \bar{b}(\bar{a}+r-u)} d r+\int_{0}^{\infty} 2 \bar{b} e^{-2 \bar{b}(\bar{a}+r-u)} d r,
$$

from which the result readily follows.

The following is a special case $(u=0)$ of Theorem 4 , which has broad application in Kolmogorov-Smirnov statistics.

THEOREM 4.a. If $\{Y(s, t):(s, t) \in D\}$ is the two-parameter Brownian bridge and if $a, b, c, d \geqq 0$, then

$$
\begin{aligned}
& P\left\{\sup _{D} Y(s, t)-(a s t+b s+c t+d)\right.\geqq 0\} \\
& \geqq \begin{cases}\frac{\vec{b}}{b}\left(e^{-\overline{2 a} \bar{c}}-e^{-\overline{2 a} \bar{b}}\right)+e^{-2 \bar{a} \bar{b}} & , \quad b>0 \\
(1+2 \bar{a} \bar{c}) e^{-\overline{2 a} \bar{b}} & , \quad b=0 .\end{cases}
\end{aligned}
$$

THEOREM 5. If $a, b, c, d \geqq 0$, then

$$
\begin{aligned}
P\left\{\sup _{D} X(s, t)-(a s t+b s+c t+d) \geqq 0\right\} & \\
\geqq & \left\{\begin{array}{rc}
N(-\bar{a})+\frac{\bar{b}}{b}\left[N(\bar{a}-2 \bar{c}) e^{-\overline{2 c}(a+b)}-N(\bar{a}-2 \bar{b}) e^{-2 a \bar{b}}\right] & \\
+N(\bar{a}-2 \bar{b}) e^{-2 \bar{a}}, & b>0 \\
N(-\bar{a})+\frac{2 \bar{c}}{\sqrt{2 \pi}} e^{-\bar{a}^{2} / 2}+N(\bar{a}-2 \bar{c})\left(1+2 \bar{a} \bar{c}-4 \bar{c}^{2}\right) e^{-2 \bar{a}}, & \\
& b=0 .
\end{array}\right.
\end{aligned}
$$

In particular,

$$
\begin{aligned}
P\left\{\sup _{D} X(s, t)-\lambda \geqq 0\right\} & \geqq 2\left[\left(1-\lambda^{2}\right) N(-\lambda)+\frac{\lambda}{\sqrt{2 \pi}} e^{-\lambda^{2} / 2}\right] \\
& =2\left[N(-\lambda)+\lambda \int_{\lambda}^{\infty} N(-s) d s\right], \quad \lambda \geqq 0 .
\end{aligned}
$$

Proof. The theorem now can be established by integrating lower estimates of the conditional probability $P_{4}$ in Theorem 4 with respect to $d P\{X(1,1) \leqq u\}=d N(u)=(2 \pi)^{-1 / 2} \exp \left(-u^{2} / 2\right) d u$. The special case when $a=b=c=0$ and $d=\lambda$ agrees with Goodman's result (Theorem 3 in [3]).

In order to find sharper upper bounds for the barrier-crossing 
probabilities we introduce the following: Let $f(s, t)$ be a continuous function on $D$. If $\sup _{D} X(s, t)-f(s, t) \geqq 0$, then define $\tau_{f}=\left(s_{0}, t_{0}\right)$ where

$$
\begin{aligned}
& s_{0}=\inf \{s \in[0,1] \mid X(s, t)=f(s, t) \text { for some } t \in[0,1]\} \\
& t_{0}=\inf \left\{t \in[0,1] \mid X\left(s_{0}, t\right)=f\left(s_{0}, t\right)\right\}
\end{aligned}
$$

while if $\sup _{D} X(s, t)-f(s, t)<0$, then set $\tau_{f}=(\infty, \infty)$. Thus with the convention that $\left(s_{1}, t_{1}\right) \leqq\left(s_{2}, t_{2}\right)$ if and only if $s_{1} \leqq s_{2}$ and $t_{1} \leqq t_{2}$, we have that

$$
P\left\{\sup _{D} X(s, t)-f(s, t) \geqq 0\right\}=P\left\{\tau_{f} \leqq(1,1)\right\} .
$$

THEOREM 6. If $c, d \geqq 0$, then

$$
\begin{aligned}
& P\left\{\sup _{D} X(s, t)-(c t+d) \geqq 0\right\} \\
& \quad \leqq 2 P\left\{\sup _{0 \leqq t \leqq 1} X(1, t)-(c t+d) \geqq 0\right\} \\
& \quad=2[1-N(c+d)+\exp (-2 c d) N(a-b)] .
\end{aligned}
$$

Proof. Let $\tau$ stand for $\tau_{f}$ when $f(s, t)=c t+d$. Define

$$
F(s, t) \equiv P\{\tau \leqq(s, t)\}
$$

Then

$$
\begin{aligned}
F(1,1) & =P\left\{\sup _{D} X(s, t)-(c t+d) \geqq 0\right\} \\
= & P\left\{\sup _{0 \leqq t \leqq 1} X(1, t)-(c t+d) \geqq 0\right\} \\
& +P\left\{\sup _{0 \leq t \leq 1} X(1, t)-(c t+d)<0, \sup _{D} X(s, t)-(c t+d) \geqq 0\right\} \\
= & P\left\{\sup _{0 \leqq t \leqq 1} X(1, t)-(c t+d) \geqq 0\right\} \\
& +\int_{0}^{1} P\left\{\sup _{0 \leqq t^{\prime} \leqq 1} X\left(1, t^{\prime}\right)-\left(c t^{\prime}+d\right)<0 \mid \tau=(s, t)\right\} d F(s, t) \\
\leqq & P\left\{\sup _{0 \leqq t \leqq 1} X(1, t)-(c t+d) \geqq 0\right\} \\
+ & \int_{0}^{1} P\{X(1, t)-(c t+d)<0 \mid \tau=(s, t)\} d F(s, t) .
\end{aligned}
$$

On account of the fact that $\tau=(s, t)$ implies $X(s, t)=c t+d$ and $X(1, t)-X(s, t)$ is independent of the conditioning $\tau=(s, t)$, it follows that 


$$
\begin{aligned}
& \int_{0}^{1} P\{X(1, t)-(c t+d)<0 \mid \tau=(s, t)\} d F(s t) \\
& \quad=\int_{0}^{1} P\{X(1, t)-X(s, t)<0\} d F(s, t)=\frac{1}{2} F(1,1)
\end{aligned}
$$

The theorem now follows readily from (3.7) and (3.8).

CoROLlaRy 6.1. If $b, c, d \geqq 0$, then

$$
\begin{aligned}
& P\left\{\sup _{D} X(s, t)-(b s+c t+d) \geqq 0\right\} \\
& \quad \leqq 2 P\left\{\sup _{0 \leqq t \leqq 1} X(1, t)-\left(b^{*} t+d\right) \geqq 0\right\}, \quad b^{*}=\max \{b, c\} .
\end{aligned}
$$

Proof. The result follows immediately by observing that

$$
\begin{gathered}
P\left\{\sup _{D} X(s, t)-(b s+c t+d) \geqq 0\right\} \\
\leqq \min _{2}\left\{P\left[\sup _{D} X(s, t)-(b s+d) \geqq 0\right],\right. \\
\left.P\left[\sup _{D} X(s, t)-(c t+d) \geqq 0\right]\right\} .
\end{gathered}
$$

The right-hand side of (3.9) can also serve as an upper bound of $P\left\{\sup _{D} X(s, t)-(a s t+b s+c t+d) \geqq 0\right\}$, and it is certainly a substantial improvement over (1.9). We state this fact formally as a corollary.

Corollary 6.2. If $a, b, c, d \geqq 0$, then

$$
\begin{gathered}
P\left\{\sup _{D} X(s, t)-(a s t+b s+c t+d) \geqq 0\right\} \\
\leqq 2 P\left\{\sup _{0 \leqq t \leqq 1} X(1, t)-\left(b^{*} t+d\right) \geqq 0\right\} \\
\leqq 2 P\left\{\sup _{0 \leqq t \leqq 1} X(1, t)-d \geqq 0\right\}=4 N(-d),
\end{gathered}
$$

where $b^{*}=\max \{b, c\}$.

4. Supremum over rectangular regions. Some adjustments are needed to apply the results for the more general rectangular region $Q=[0, S] \times[0, T]$. The conversion formulas are given by:

$$
\begin{aligned}
& P\left\{\sup _{\partial Q} X(s, t)-(a s t+b s+c t+d) \geqq 0\right\} \\
& =P\left\{\sup _{\partial D} X(s, t)-\left(a^{\prime} s t+b^{\prime} s+c^{\prime} t+d^{\prime}\right) \geqq 0\right\},
\end{aligned}
$$

where $a^{\prime}=a \sqrt{S T}, b^{\prime}=b \sqrt{S / T}, c^{\prime}=c \sqrt{T / S}$, and $d^{\prime}=d / \sqrt{S T}$. 


$$
\begin{aligned}
& P\left\{\sup _{Q} X(s, t)-(a s t+b s+c t+d) \geqq 0 \mid X(S, T)=u\right\} \\
& \quad=P\left\{\sup _{D} X(s, t)-\left(a^{\prime} s t+b^{\prime} s+c^{\prime} t+d^{\prime}\right) \geqq 0 \mid X(1,1)=u^{\prime}\right\},
\end{aligned}
$$

where $a^{\prime}, b^{\prime}, c^{\prime}, d^{\prime}$ are as in (4.1) and $u^{\prime}=u / \sqrt{S T}$. In (4.1), if $\partial Q$ is replaced by $Q$, then $D$ replaces $\partial D$.

\section{REFERENCES}

1. A. H. C. Chan, Some lower bounds for the distribution of the supremum of the Yeh-Wiener process over a rectangular region, J. Appl. Prob., 12 (1975), 824-830.

2. J. L. Doob, Heuristic approach to the Kolmogorov-Smirnov theorems, Ann. Math. Stat., 20 (1949), 393-403.

3. V. Goodman, Absorption probability estimates for vector-valued Brownian motion and distribution estimates for functionals of the two-parameter Wiener process, Annals of Prob., 6 (1976), 977-982.

4. J. Kiefer, On large deviations of the empiric d.f. of vector chance variables and a law of the iterated logarithm, Pacific J. Math., 11 (1961), 649-660.

5. S. Malmquist, On certain confidence contours for distribution functions, Ann. Math. Stat., 25 (1954), 523-533.

6. S. R. Paranjape and C. Park, Distribution of the supremum of the two-parameter Yeh-Wiener process on the boundary, J. Appl. Prob., 10, No. 4, (1973), 875-880.

7. __ Laws of iterated logarithm of multiparameter Wiener processes, J. Mult. Anal., 3 (1973), 132-136.

8. J. Yeh, Wiener measure in a space of functions of two variables, Trans. Amer. Math. Soc., 95 (1960), 433-450.

9. - Stochastic Processes and the Wiener Integral, Marcel Dekker, Inc., N.Y. (1973).

Received October 30, 1977 and in revised form March 9, 1978.

MiAMI UNIVERSITY

OXFORD, OH 45056

AND

UNIVERSITY OF NEBRASKA

LINCOLN, NE 68588 


\title{
PACIFIC JOURNAL OF MATHEMATICS
}

\section{EDITORS}

RICHARD ARENS (Managing Editor)

University of California

Los Angeles, CA 90024

Charles W. Curtis

University of Oregon

Eugene, OR 97403

C. C. MOORE

University of California

Berkeley, CA 94720

\section{J. DUGUNDJI}

Department of Mathematics University of Southern California Los Angeles, CA 90007

R. Finn and J. Milgram

Stanford University

Stanford, CA 94305

\section{ASSOCIATE EDITORS}
E. F. BECKENBACH
B. H. NeumanN
F. WOLF
K. YOSHIDA

\section{SUPPORTING INSTITUTIONS}

\author{
UNIVERSITY OF BRITISH COLUMBIA \\ CALIFORNIA INSTITUTE OF TECHNOLOGY \\ UNIVERSITY OF CALIFORNIA \\ MONTANA STATE UNIVERSITY \\ UNIVERSITY OF NEVADA, RENO \\ NEW MEXICO STATE UNIVERSITY \\ OREGON STATE UNIVERSITY \\ UNIVERSITY OF OREGON
}

\author{
UNIVERSITY OF SOUTHERN CALIFORNIA \\ STANFORD UNIVERSITY \\ UNIVERSITY OF HAWAII \\ UNIVERSITY OF TOKYO \\ UNIVERSITY OF UTAH \\ WASHINGTON STATE UNIVERSITY \\ UNIVERSITY OF WASHINGTON
}

The Supporting Institutions listed above contribute to the cost of publication of this Journal, but they are not owners or publishers and have no responsibility for its content or policies.

Mathematical papers intended for publication in the Pacific Journal of Mathematics should be in typed form or offset-reproduced, (not dittoed), double spaced with large margins. Please do not use built up fractions in the text of the manuscript. However, you may use them in the displayed equations. Underline Greek letters in red, German in green, and script in blue. The first paragraph or two must be capable of being used separately as a synopsis of the entire paper. Items of the bibliography should not be cited there unless absolutely necessary, in which case they must be identified by author and journal, rather than by item number. Manuscripts, in triplicate, may be sent to any one of the editors. Please classify according to the scheme of Math. Reviews, Index to Vol. 39. All other communications should be addressed to the managing editor, or Elaine Barth, University of California, Los Angeles, California, 90024.

50 reprints to each author are provided free for each article, only if page charges have been substantially paid. Additional copies may be obtained at cost in multiples of 50 .

The Pacific Journal of Mathematics is issued monthly as of January 1966. Regular subscription rate: $\$ 72.00$ a year (6 Vols., 12 issues). Special rate: $\$ 36.00$ a year to individual members of supporting institutions.

Subscriptions, orders for numbers issued in the last three calendar years, and changes of address should be sent to Pacific Journal of Mathematics, P.O. Box 969, Carmel Valley, CA 93924, U.S.A. Older back numbers obtainable from Kraus Periodicals Co., Route 100, Millwood, NY 10546.

PUBLISHED BY PACIFIC JOURNAL OF MATHEMATICS, A NON-PROFIT CORPORATION

Printed at Kokusai Bunken Insatsusha (International Academic Printing Co., Ltd.). 8-8, 3-chome, Takadanobaba, Shinjuku-ku, Tokyo 160, Japan.

Copyright (C) 1978 by Pacific Journal of Mathematics Manufactured and first issued in Japan 


\section{Pacific Journal of Mathematics \\ Vol. 78, No. $2 \quad$ April, 1978}

Su-Shing Chen, Weak rigidity of compact negatively curved manifolds .... 273

Heinz Otto Cordes and D. A. Williams, An algebra of pseudodifferential operators with nonsmooth symbol ....................... 279

Herbert Paul Halpern, Normal expectations and integral decomposition of type III von Neumann algebras ......................... 291

G. Hochschild, On representing analytic groups with their

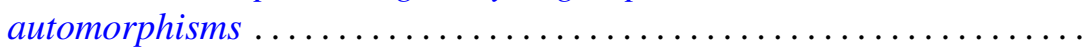

Dean G. Hoffman and David Anthony Klarner, Sets of integers closed under affine operators - the closure of finite sets ....................

Simeon Ivanov, On holomorphic relative inverses of operator-valued

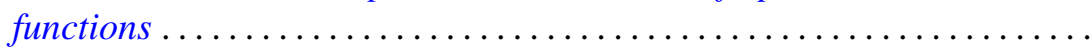

O. P. Juneja and M. L. Mogra, Radii of convexity for certain classes of

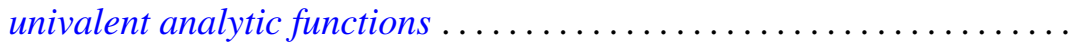

Hadi Kharaghani, The evolution of bounded linear functionals with application to invariant means.......................... 369

Jack W. Macki, A singular nonlinear boundary value problem .......... 375

A. W. Mason and Walter Wilson Stothers, Remarks on a theorem of $L$. Greenberg on the modular group ........................ 385

Kevin Mor McCrimmon, Peirce ideals in Jordan algebras . . . . . . . . . . . 397

John C. Morgan, II, On the absolute Baire property ................ 415

Gerard J. Murphy, Commutative non-Archimedean $C^{*}$-algebras ...

Masafumi Okumura, Submanifolds with L-flat normal connection of the

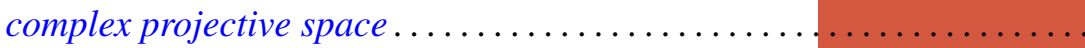

Chull Park and David Lee Skoug, Distribution estimates of barrier-crossing probabilities of the Yeh-Wiener process ...............

Irving Reiner, Invariants of integral representations ........

Phillip Schultz, The typeset and cotypeset of a rank 2 abelian group ..... 503

John Brendan Sullivan, Representations of Witt groups ....

Chia-Chi Tung, Equidistribution theory in higher dimensions . . . 